\title{
UNDERSTANDING DESIGN APPROACH FOR BILINGUAL ROADWAY DIRECTIONAL SIGN
}

\author{
Reynaldo Siahaan ${ }^{1,}$ Jamiel Louiee Jayme ${ }^{2}$ \\ ${ }^{1}$ Study Program of Civil Engineering, Catholic University of Saint Thomas, Indonesia, email: \\ siahaan.reynaldo@gmail.com \\ ${ }^{2}$ Civil Engineering, De La Salle University, Philippines, email: jemjayme@yahoo.com
}

\begin{abstract}
The use of bilingual roadway directional sign is getting more important worldwide. It is triggered by the increasing concerns about the importance of providing the same information for foreigners as locals. However, while some countries have set their regulations and standards, there is still no general standard produced in the market about the adequate design for the bilingual roadway directional signs. This study explores available standards and discusses some issues concerned by comparing various bilingual directional signs practices in different countries and analyzing them based on related theories and past studies. Several similarities and consistencies were found in many countries, and thus particular guidance in the design approach for bilingual road directional sign is concluded. The design approach should pay attention to text volume, order, physical distinction, and also familiarity.
\end{abstract}

Keywords: bilingual directional signs, urban road sign, friendly city

\section{Introduction}

Roadway signs are one of the most important components on the urban roadway because it provides information and guidance for drivers. Roadway signs are not only used for traffic control, but also for directional guide purpose. Traffic control devices, such as roadway traffic signs, prevent traffic accidents, and improve road safety. Whereas, directional roadway signs are intended to prevent confusion and ambiguity when drivers or road users are trying to find their way and destination. Road signs typically designed in color decoding forms that represent priority or designated purpose. This coloring system is not the same in every continent/region, and in fact, most countries standardize their roadway sign design. In contrast, others make some adaptation from existing standards (such as the US MUTCD). Such directional sign is usually displayed in static form. There was no significant difference between the static and alternating display (Anttila et al., 2000; Castro \& Horberry, 2000); however, the consensus in many countries is to use the static one.

Generally, most urban roadway signs are provided in only one language, which is the country's official language. These roadway signs are currently intended to serve local people. However, for countries in Southeast Asia, economic development is gradually attracting workers from outside the country who also bring their family to become new inhabitants. It is fair to say that inadequate roadway signs could eventually become a problem when the number of foreign inhabitants (ex-pats, tourists, etc.) in the city grows. Currently, bilingual roadway signs are mostly used in countries where there is a significant equal status of two major languages or regions whose native language does not use the Roman alphabet. As the concern of providing the same information for foreigners increases, the use of more than a single language for urban roadway sign achieves more attention.

In today's era, English is the universal language used in almost any aspect; this includes transportation facilities or specifically: roadway signs. Roadway directional signs provide directional messages on roads or highways in local or English language. However, in some countries, local or accepted foreign languages, which are not necessarily in English, are used to deliver messages on roads. The use of bilingual signs will aid road users in their daily mobility inside the city. The use of bilingual directional signs on roads and highways will not only help local area users find their location but also assist foreigners or tourists to easily fulfill their travel needs.

Focusing on road users, in this study, we are inclined to discuss mainly on drivers for both motorcycles and also cars. However, the issue we are discussing in this article may also apply to the pedestrian in particular cases. It was found that multiple text display affects driving behavior, including speed (Jamson, 2005). Seeing unfamiliar words is also considered affecting drivers' reading time since it relatively distracts their attention from the more familiar ones. This would be a negative effect on 
local road users (Tejero, 2019). Further, drivers' cognition toward texts on roadway signs potentially influences their driving performance as the result of attention reduction to the traffic; thus, it may endanger their safety (Lyu et al., 2017; Metz, Kruger, 2014). However, it was also studied that bilingual signs apparently increase driving tasks but not significantly increase accident risk (Kinnear et al., 2012). As the ultimate purpose of roadway signs is to efficiently deliver the message and aid drivers, there are several key criteria that need to be addressed. Criteria such as type of letters (capitalize-or non-), text height and spacing, text styles, are equally important in order to ensure instant message comprehension. Reducing drivers' cognition time means ensuring longer attention to the traffic. This will satisfy both the ultimate purpose of roadway signs and also road safety. In this paper, the authors will discuss the plausible approach in designing the convenient bilingual roadway sign based on past studies and observations made during this study.

\section{2. $\quad$ Related Literature}

Roadway signs, especially traffic-related signs, usually use pictures or symbols to guide drivers. In some cases, the addition of text is important since not all drivers could freely understand the meaning (Horberry, 2004; Shimar \& Vogelzang, 2013). Directional road signs even possess more needs for text, as the name of places could not be described in images alone. However, standardization is needed in relation to including texts to roadway signs. Text standardization includes allowing precisely only the most important texts and removing insignificant or redundant texts (Bartłomiejczyk, 2013). Furthermore, considering ergonomic principles (such as physical and conceptual compatibility, standardization, familiarity) would be much more helpful in improving driver's comprehension. This is the first issue of directional roadway signs (Ben-Bassat \& Shinar, 2006).

Drivers' reading time is mainly affected by the appearance of the message on the board, which includes whether it is bilingual or monolingual. Jamson (2004) found that bilingual signs that consist of four-line texts significantly increased reading time. General socio-economic variables such as gender, age, and driving experience do not significantly affect the driver's interpretation of road signs. On the other hand, the country of origin has a significant effect (Nygårdhs \& Helmers, 2007). Different bilingual countries use different standards depending on the local government, whether to follow the MUTCD standards on road signs or have their own standards.

A specific issue can be found in countries that use Non-Romanized letters in their official written language. Translating the texts into Romanized letters could potentially distract local drivers, but on the other hand, help the foreign driver. However, it was studied that young drivers (with Chinese proficiency) in China paid less attention to the Romanized translation and reported that it offers no help for them. On the other hand, the foreigner (without Chinese proficiency) stated that the Romanized translation was not helpful either, due to insignificant display proportion (Yang, 2019). Standardization and language policy hold a crucial role. In some countries (for instance, Oman), there is an inconsistency pertaining to Romanization and its implementation in roadway signs, which causes confusion and less familiarity both for local people and foreigners (Jamoussi, 2017 \& Zhang, 2018).

\subsection{Non-Romanized-Letter Signs}

Countries that have languages that use special characters rather than the Roman alphabet may have their own requirements in providing road directional sign standards. For bilingual directional signs, most of the countries under this category incorporate the English language to their road signs to be able to guide foreigners to travel. Countries like China and Thailand in Asia and also Arabic countries in the Middle East commonly use bilingual signs to help foreigners and improve the internationalized atmosphere. The difference in the text style is relatively a good point for a foreigner because it is easier to recognize the more understandable text. However, transliteration into Romanized letters could also drive a problem.

Most of the countries with Non-Roman letters are found in Asia. In China, the use of bilingual directional signs is mandatory generally in the autonomous regions, but most of these regions do not necessarily use English as the second language for their signs, depending on the minor language that shares with the official language of China. For the major cities in China or cities exposed to international events, the use of English as the second language for most of their signs is growing. However, offering translation in Romanized Pinyin, which is the standardized Chinese transliteration, could cause even more confusion and not a helpful alternative for the foreigner. It would be much more desirable to use Romanized English (Zhang, 2018). English translation issue also applies to the country in Southeast Asia, such as Thailand, who commonly utilizes bilingual road signs. Thailand (Fig. 
Jurnal Arsitektur AIUR - Vol 3 No 1 Mei 2020

e-ISSN 2685-1490; p-ISSN 2615-1472

1c) slightly offer better condition than China (Fig. 1b) for a foreigner because the translation is made for all words, except for the name of places.

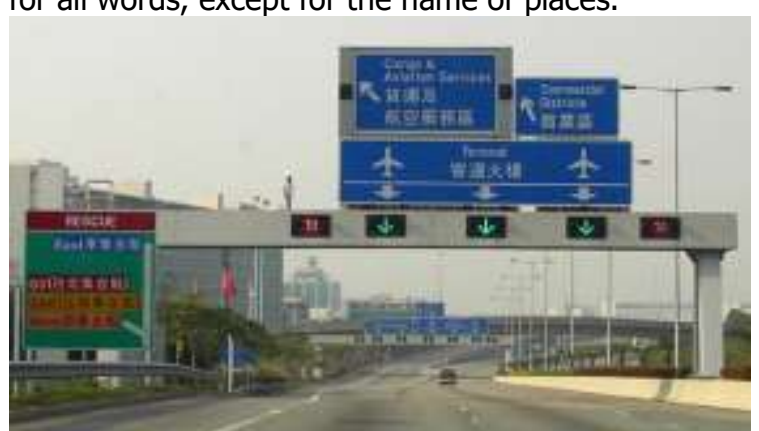

(a)

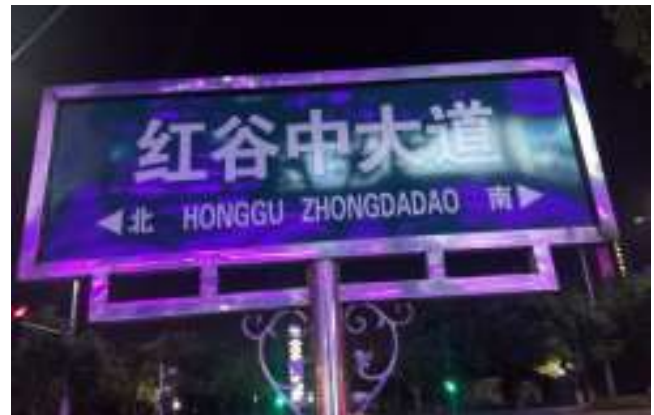

(b)

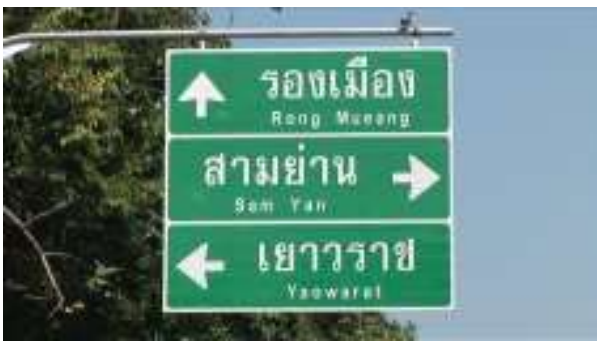

(c)

Figure 1. (a) Hong Kong bilingual directional $\operatorname{sign}^{[1]}$; (b) Romanized pinyin directional sign in China ${ }^{[2]}$.

(c) Transliterated road sign for the name of the place in Thailand ${ }^{[3]}$

In the Middle East, countries also have their own Non-Romanized alphabet, but most directional road signs that they use have the English translation or use English as their second language to deliver messages on roads. Most countries in the world with these kinds of situations, especially in Asia, follow similar practices as mentioned above, and only some of them produce their own standardized requirements.

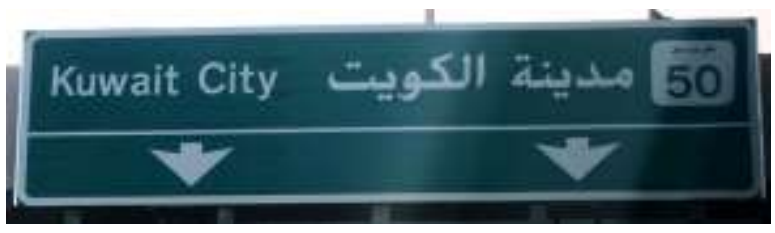

Figure 2. Kuwait Bilingual Directional Sign ${ }^{[4]}$

\subsection{Romanized-Letter Signs}

Meanwhile, countries that use the Roman alphabet for their main language but not specifically English have progressed to the use of a bilingual system. Most of these countries are in the West part of the world due to the higher amount of international travel and workers, and also in lieu of the sensitivity to the needs of linguistic minorities. In Ireland, for example, most of the signs used in towns, buildings, and roads have both Irish and English languages. In Wales, official languages used are Welsh and English. In Slovenia, other than Slovene, there are many official languages used in different regions like Italian and Hungarian, and it is required by the government to include all the official languages on all official signs.

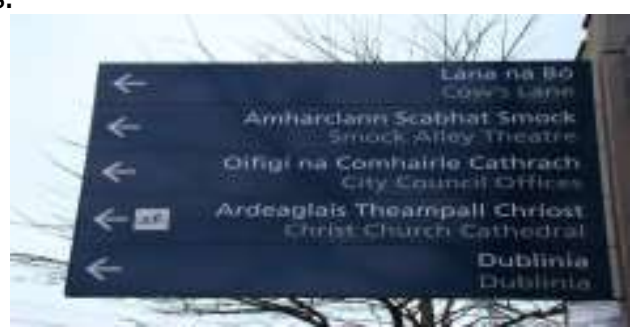


Figure 3. Ireland Bilingual Directional Sign ${ }^{[5]}$

The implementation of bilingual signs where both languages are in the Romanized alphabet has its own advantages and disadvantages. As previously mentioned in the previous subsection, foreign drivers tend to read the most familiar text displayed on the sign. Therefore, they can easily find written language that they understand between Romanized and non-Romanized character. This is one of the disadvantages of using the bilingual sign in countries that use the Romanized alphabet. The displayed bilingual texts (or more) should be simple enough to distinguish in order to lessen reading and response time. On the other hand, having bilingual text with the same form of the alphabet might help foreign drivers in particularly some rare but real cases. Foreign drivers with no particular English literacy could verify the destination that they are looking for by comparing his written address to the displayed directional sign directly. It would be very difficult if it were in Arabic or Thai or Chinese written character.

\subsection{Design}

According to previous studies, the use of bilingual directional signs requires road users more time to read compared to using monolingual directional signs (Lesage,1981). It was previously discussed that texts in non-Romanized alphabet bilingual directional signs are more comfortable to discern because of the obvious shape difference between the languages. Therefore, in most practices, we observed that no particular design demarcation (color, shape, style) is applied in such type of bilingual signs. The most common design practice is solely related to text height. Countries tend to utilize the same text height in their bilingual road signs (see Fig. $4 a$ and $4 b$ ). Some make a slight modification by putting bigger text for their local official language than the English (or foreign) language. The previous examples (see Fig. 1) in China also show different modifications where the local official language is written in significantly bigger text height than the foreign language texts.

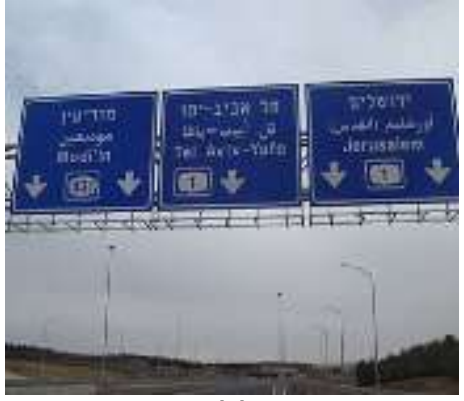

(a)

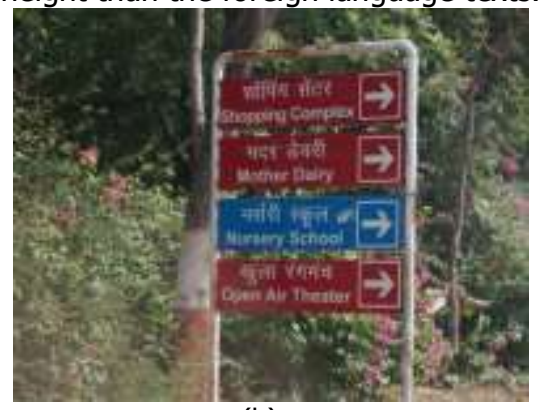

(b)

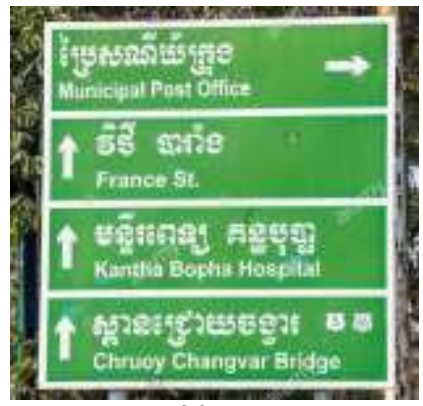

(c)

Figure 4. (a) Greek bilingual road sign ${ }^{[6]}$; (b) Hindi bilingual road sign ${ }^{[7]}$;

(c) Khmer (Cambodian) bilingual road sign ${ }^{[8]}$

On the other hand, there should be a lot more text distinction between languages when both languages are in the Romanized alphabet. The design features found in directional signs have standards and requirements to be able to relay or deliver the message to road users with comfort and safety. (Jamson \& Mrozek, 2017) studied responses of drivers from 3 different countries and concluded that text colors and shapes standards are the most defining criteria for aiding drivers' comprehension.

The US Manual of Uniform Traffic Control Devices (MUTCD) provides all the standards for roadway directional guide signs regarding the text style, text size, and color. The MUTCD standard of the text color for a directional sign is white in a green background. However, when it comes to the Non-Roman alphabet, the font style and size may differ for different countries with different alphabets.

The color of the messages written on the signs indicates the importance of the message to be delivered. Jamson (2004) evaluated the importance of applying demarcation (using font, color, font case, and separation) in on improving driver's response time. It was further reported that there is no statistical difference in response time between single line monolingual text and two-line bilingual text. A similar study was conducted by Lansdown (2004) and reported that the design of the bilingual sign should consider several factors, including position, typographic features, color, and reflective/refractive properties.

In some countries, they follow their own standards and may use different color schemes for the written texts. An example of which is the bilingual directional sign in Dublin, Ireland, the Irish language is in color yellow while the English translation is in color white. It may indicate the hierarchy of importance of language usage in the country, but it may not apply to all countries using similar standards. 
Jurnal Arsitektur AIJR - Vol 3 No 1 Mei 2020

e-ISSN 2685-1490; p-ISSN 2615-1472

In relation to the number of message lines and lines order, having international standards are very unlikely and may be different for every situation. In Rutley (1974), it is advisable to put English above Welsh Gaelic language. However, in this particular case, most Irish people are more familiar with English than Gaelic. Therefore, it might not be the same in other countries. It can be interpreted that putting the most familiar language on the first order is more applicable. Furthermore, in other related studies, it was found that guide signs with five or more lines of information visual cognition decrease significantly, and the duration of the driver's perception increases (Lai, 2010). There is also a study about the comprehension of the bilingual texts on the signs, where to put the dominant language and the minor language. There are significant results for the dominant language to be located at the "top" of a "top-bottom" configuration and "left" of a "left-right" configuration. However, either of the two configurations was found significantly better than the other (Lesage, 1981).

\section{Methodology}

In order to understand the type and recommended approach of the bilingual directional sign, we conducted observations through various literature on roadway directional signs in several countries. Literature such as past studies and field images were drawn out from the Internet through scientific journal database (Google Scholar), and/or news article from observed countries. We are interested in both countries that use Romanized and countries that use the non-Romanized letter in their official written languages. The aim of this observation is to compare typical practices to scientific recommendations. Most past scientific studies focused on the behavioral responses of drivers regarding the cognition of bilingual directional signs. Therefore, we may understand the best approach in designing a legible directional roadway sign.

The second part of this study is a preferential survey. In this study, we conducted a simple survey to elicit people's preference in relation to the design of the bilingual directional sign. Targeted respondents were comprised of diverse nationalities whose official languages utilize Roman or nonRomanized alphabet. The main objective was to collect their perceptional responses based on visual clearness and reading convenience.

A set of two-section questionnaire was given to random respondents on the Internet. The first section was for general socio-demographic information, whereas the second section was dedicated to collect the main information needed. In the second section, respondents were asked to rank their choice of bilingual directional sign assuming they were driving on a road section as being pictured. Based on current worldwide practices, bilingual directional signs are presented in two lines. One of the lines represents the local language, whereas the other one represents international language such as English. The most common practice is to modify text colors, font styles, and text height. In this survey, we opted to combine font style variation and text color variation. In terms of lines order, we follow current practices and Jamson (2004), where the most familiar language is put on the first line, and English (for the non-English-speaking country) is put on the second (bottom) line. Therefore, the respondents were given four different kinds of designs as follows:

1. Different font style (one italic, one normal) - Different color

2. Same font style (both normal) - Different color

3. Different font style - Same color

4. Same font style - Same color

The objective of this survey is to collect people's choice pertaining to the type of design of bilingual directional signs they are most comfortable with. The expected result is that people will most likely choose design No.1 on top of their rank and will put design No.4 as the least preferable. The sample of the visual simulation choice set can be seen in the following pictures. 


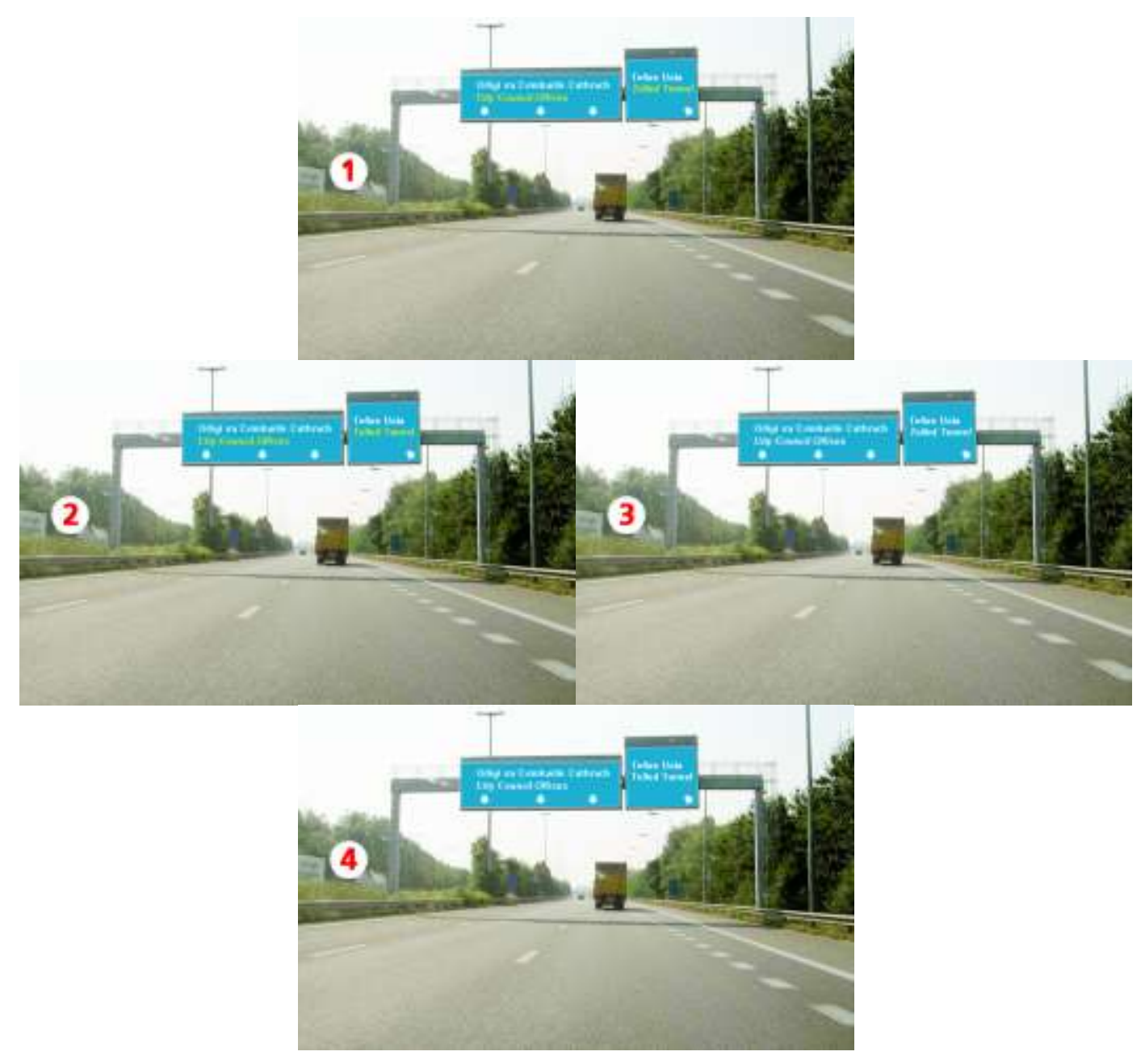

Figure 5. Sample Directional Sign used in the Online Questionnaire

\section{Discussion}

\subsection{Advisable Design Approach}

Looking at these two different types of letters, the concern and importance regarding bilingual directional signs are different as well. As an example, we can see previously in Fig. 2 an example of a directional sign in Kuwait. As a foreigner driver, we may easily just ignore the non-roman letter and read the writing in a roman letter, which in this case is an English translation. The amount of reading time for readers might not actually be affected. In fact, it might not have a significant effect on reading time if there were more than one writings in the non-Romanized letter. Foreigners will generally focus on the writing they can understand, which is, in most cases, the roman style. Moreover, it is a different case when the driver can read both roman and non-roman letter style.

More serious concern and importance are found in the Romanized letter bilingual sign. The amount of reading time is affected significantly because both writings are in the same style. Drivers need more time to find the language they understand and then read it afterward. This is also probably the reason why most previous studies focused their observations on roman-letter bi- and multi-lingual signs. Focusing on this issue, we have proposed an early discussion in this article in relation to the importance of text demarcation. In order to ensure less reading time and improve driver's comprehension, clear distinctions should be made between the two languages. Jamson (2004) and Lansdown (2004) proposed a similar recommendation based on their subsequent studies. However, the nature of the driver's country of origin and language literacy should also be considered no less essential. Future studies that involve more drivers' nationality variation would be very useful to address 
Jurnal Arsitektur AIJR - Vol 3 No 1 Mei 2020

e-ISSN 2685-1490; p-ISSN 2615-1472

this concern. Alternatively, a cross-country evaluation would also produce an interesting result to support our understanding.

In relation to traffic and directional signs in an internationally exposed environment, such as developing cities, it is important to have consistency design. Local and foreign drivers should easily understand the signs wherever they travel both inside the city and inter-city. Having clear and consistent standardization is paramount in this regard. It is advisable that authority and policymaker should provide standards to be followed in every city, especially major cities where most foreigners live and work. Based on current practices in various countries and past studies, bilingual directional sign standards should, at the very least, include volume and order, familiarity, physical distinction, and lastly, optional pictorial aid.

Providing the directional signs with the same feature style wherever they go should assist the foreign driver. Volume represents the number of texts presented on the board. The more text on the board means more gazing and reading time. The order represents text positions on the board. It is widely recommended that more familiar language should be above the foreign language. In this case, it would very much depend on the country and its official language. Familiarity represents the use of generally accepted words. It was studied that the reading and response time of the drivers may be negatively affected by the need to process unheard words. The physical distinction represents background color, text color, text style, text height, the distance between text, and etc. Optionally, images and illustrations can be utilized in order to assist the driver's comprehension toward certain word complication (Ells, 1979).

Based on the review from studies in the past, various kinds of font modifications and configurations (top or bottom; left or right) are apparently the most intense part of the study to find out the best design for a bilingual directional sign (Smahel \& Smiley, 2011; Kinnear, 2012; Bartłomiejczyk, 2013) This tendency is very logical because those aspects are really related to driver's eye movement and response in the process. Font colors and certain placement on the board are applied to make the main language and the foreign language look different. It is agreeable to say that the more difference between one written language to another, the easier it is to be distinguished and to be read by the driver.

Through related observations, the standards for a bilingual directional sign can be adapted from the standards of MUTCD with some adjustments and modifications. MUTCD is already ahead and has a wide range of standardization in traffic control devices such as road signs. By providing some justifications for each type of multi-lingual country, the standards may be unified to avoid confusion to road users.

4.2 Survey Result

Our main objective in this survey was to understand the driver's preference based on their comfort while reading the directional sign. We collected 20 non-English natives to test the provided bilingual signs. We intentionally asked drivers with no particular literacy on the local language to test the directional signs. This is to ensure that they experience the confusion and processing time in order to find more familiar words on the board. The result of this survey shows that people prefer design No. 1 (Different font style-Different color) the most. Even though design No.1 and 2 share the same proportion (37.5\%) of people's choice, this result still satisfies our expectations and the objective. Design No.1 has more factors that distinguish the local language with the English translation, so it is more comfortable for drivers, especially foreigners, to read it. On the other hand, Design No.2 only distinguishes the bilingual messages in colors, but respondents still tend to choose this type as their first choice. From this result, we can draw an early hypothesis that the font style does not have a significant effect on people's reading comfort. Changing font style, as the difference between two languages, may not really effective to be implemented. On the other hand, color has a significant effect on people's eyes.

The other key point is that design No.4 (same font style-same color) has the lowest proportion of being chosen as the best design. In fact, most respondents (82\%) put this design as the last rank. This design is, in fact, uncomfortable to read because there are no factors that distinguish the local language with the English translation. People would most likely spend more time to find and process the information written. This survey result proposes that differentiating the font colors may be an effective way to reduce reading time because it is reported as more comfortable for the driver to read.

\section{Conclusion}

This study explored the current practice and design of bilingual directional signs and their specifications. Developing countries (i.e., Indonesia and the Philippines) are experiencing an escalation 
in the number of foreigners who live and work in their major cities. The significance of having a bilingual directional sign is to provide more assistance and guidance to foreign road users (drivers) and to those linguistic minorities. Providing this bilingual sign would add more value and friendly vibe to the internationally exposed city in the long term. Through an effective observation and comparison of studies and the use of an online questionnaire survey, the most advisable design approach for a bilingual sign can be understood. Authorized consistent road sign standards should be of concern to policymakers in the future in order to ensure friendlier city for both local and foreigner. An adaptation of the US MUTCD with the help of a comprehensive literature review on past research and current practices would be a plausible step.

\section{References}

Anttila, V., Luoma, J., \& Rämä, P. (2000). Visual demand of bilingual message signs displaying alternating text messages. Transportation research part F: traffic psychology and behaviour, 3(2), 65-74.

Bartłomiejczyk, M. (2013). Text and image in traffic signs.

Ben-Bassat, T., \& Shinar, D. (2006). Ergonomic guidelines for traffic sign design increase sign comprehension. Human factors, 48(1), 182-195.

Castro, C., \& Horberry, T. (2004). The human factors of transport signs. CRC press.

Ells, J. G., \& Dewar, R. E. (1979). Rapid comprehension of verbal and symbolic traffic sign messages. Human Factors, 21(2), 161-168.

Jamson, S. L. (2004). Evaluation of techniques to improve the legibility of bilingual Variable Message Signs. Advances in Transportation Studies, 4, 71-88.

Jamson, S. L., Tate, F. N., \& Jamson, A. H. (2005). Evaluating the effects of bilingual traffic signs on driver performance and safety. Ergonomics, 48(15), 1734-1748.

Jamson, S., \& Mrozek, M. (2017). Is three the magic number? The role of ergonomic principles in cross country comprehension of road traffic signs. Ergonomics, 60(7), 1024-1031.

Kinnear, N., Helman, S., Buttress, S., Smith, L., Walter, L., \& Sexton, B. (2012). Analyses of the effects of bilingual signs on road safety in Scotland (No. PPR589)

Lai, C. J. (2010). Effects of color scheme and message lines of variable message signs on driver performance. Accident Analysis \& Prevention, 42(4), 1003-1008.

Lansdown, T. (2004). Considerations in the evaluation and design of roadway signage from the perspective of driver attentional allocation. In The human factors of transport signs. C. Castro and T. Horberry, CRC Press

Lesage, P. B. (1981). Design and comprehension of bilingual traffic signs (No. Monograph).

Lyu, N., Xie, L., Wu, C., Fu, Q., \& Deng, C. (2017). Driver's cognitive workload and driving performance under traffic sign information exposure in complex environments: A case study of the highways in China. International journal of environmental research and public health, 14(2), 203.

Metz, B., \& Krüger, H. P. (2014). Do supplementary signs distract the driver?. Transportation research part F: traffic psychology and behaviour, 23, 1-14.

Shinar, D., \& Vogelzang, M. (2013). Comprehension of traffic signs with symbolic versus text displays. Transportation research part F: traffic psychology and behaviour, 18, 72-82.

Smahel, T., \& Smiley, A. (2011). Evaluation of bilingual sign layout and information load before implementation of new signing system. Transportation research record, 2248(1), 37-44.

Tejero, P., Insa, B., \& Roca, J. (2019). Reading Traffic Signs While Driving: Are Linguistic Word Properties Relevant in a Complex, Dynamic Environment?. Journal of Applied Research in Memory and Cognition, 8(2), 202-213.

Yang, Y., Chen, J., Easa, S. M., Zheng, X., Lin, W., \& Peng, Y. (2020). Driving simulator study of the comparative effectiveness of monolingual and bilingual guide signs on Chinese highways. Transportation Research Part F: Traffic Psychology and Behaviour, 68, 67-78

Zhang, H. (2018). Linguistic landscape in Nanchang: A look into the biliterate street name sign. International Journal of Arts and Humanities, 4(2), 52-59

${ }^{[1]}$ [Untitled image], Retrieved from www.wikiwand.com/en/Bilingual_sign

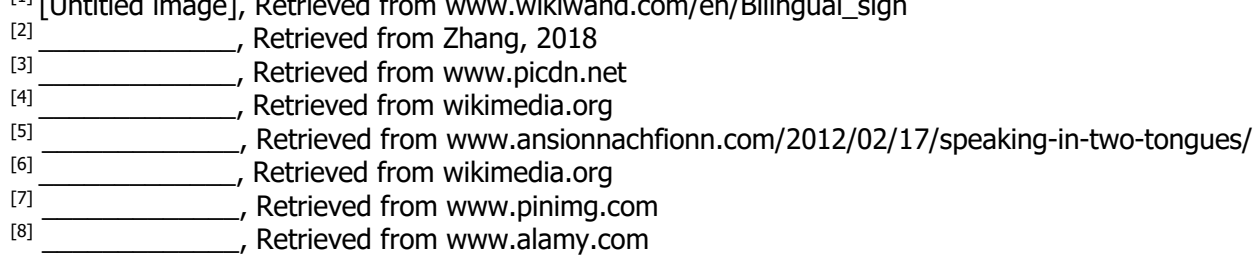

